Japanese Research on Linguistics, Literature, and Culture

ISSN online: $\underline{2655-4836}$

http://publikasi.dinus.ac.id/index.php/irllc

Published by Universitas Dian Nuswantoro, Semarang

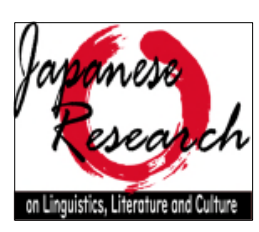

\title{
The Concept and Use of Aisatsu
}

\section{Akhmad Saifudin ${ }^{1}$}

Universitas Dian Nuswantoro, Semarang, Indonesia

\begin{tabular}{|c|c|}
\hline Article History & Abstract \\
\hline $\begin{array}{l}\text { Submitted date: } \\
\text { 2021-11-01 } \\
\text { Accepted date: } \\
\text { 2021-11-27 } \\
\text { Published date: } \\
\text { 2021-11-30 }\end{array}$ & $\begin{array}{l}\text { This paper discusses the use of aisatsu to understand the concept of aisatsu for } \\
\text { Japanese people and how Japanese people use aisatsu. The research was conducted } \\
\text { using qualitative methods with data sources in recordings and notes from } \\
\text { observations and interviews with research subjects. These namely two Japanese } \\
\text { students were taking part in summer course activities in Semarang for three days. The } \\
\text { approach used in this research is linguistic anthropology with Hvmes' ethnographic }\end{array}$ \\
\hline $\begin{array}{l}\text { Keywords: } \\
\text { aisatsu; greetings; } \\
\text { Japanese; Hymes }\end{array}$ & $\begin{array}{l}\text { theory of communication. From the results of data analysis, it was found that aisatsu } \\
\text { is used as a greeting, request for permission, an expression of the speaker's feelings, } \\
\text { both expressions of apology, gratitude, and feelings of empathy for the speech } \\
\text { partner. It was also concluded that the concept of aisatsu is a ritual related to the } \\
\text { ethics of politeness and as a sign that represents that the speaker is ready and hopes } \\
\text { that his interlocutor is also ready to be involved in the interaction. }\end{array}$ \\
\hline
\end{tabular}

\section{Kata Kunci:}

aisatsu; greetings; Jepang; Hymes

\section{Abstrak}

\section{Konsep dan Penggunaan Aisatsu}

Tulisan ini mambahas penggunaan aisatsu dalam rangka memahami konsep aisatsu bagi orang Jepang serta bagaimana orang Jepang menggunakan aisatsu. Penelitian dilakukan dengan metode kualitatif dengan sumber data berupa rekaman dan catatan hasil observasi dan wawancara terhadap subjek penelitian, yaitu dua orang mahasiswa Jepang yang sedang mengikuti kegiatan summer course di Semarang selama tiga hari. Ancangan yang digunakan dalam penelitian adalah linguistik antropologi dengan teori etnografi komunikasi Hymes. Dari hasl analisis data ditemukan bahwa aisatsu digunakan sebagai salam, permohonan izin, ungkapan perasaan penutur, baik ungkapan maaf, terima kasih, maupun perasaan empati kepada mitra tutur. Disimpulkan juga bahwa konsep aisatsu merupakan ritual yang berkaitan dengan etika kesopanan dan sebagai tanda yang merepresentasikan bahwa penutur telah siap serta berharap mitra tuturnya juga siap untuk terlibat dalam interaksi.

\section{Pendahuluan}

Salah satu fenomena yang menarik dalam bahasa Jepang adalah Aisatsu. Aisatsu yang dalam bahasa Inggris sering dipadankan dengan greetings atau dalam bahasa Indonesia dengan salam, mempunyai peran yang sangat penting dalam interaksi percakapan bahasa Jepang. Hal ini dapat diamati dengan frekuensi kemunculan aisatsu yang sangat tinggi dalam percakapan. Aisatsu muncul di awal, di tengah, dan di akhir percakapan dengan berbagai variasi tuturan, situasi, dan fungsinya. Frekuensi yang tinggi dan banyaknya variasi selain mengindikasikan betapa pentingnya fungsi, juga

Corresponding author:

${ }^{1}$ Akhmad.saifudin@dsn.dinus.ac.id 
menunjukkan bahwa aisatsu adalah sesuatu yang kompleks. Aisatsu bukan sekedar ungkapan yang digunakan untuk persalaman, seperti ohayo gozaimasu, konnichiwa, ataupun sayonara, lebih dari itu ia adalah semacam 'alat' yang harus dikuasai oleh pengguna bahasa Jepang karena sangat berkaitan dengan harmoni dalam komunikasi sosial.

Istilah aisatsu secara bahasa terbentuk dari dua karakter Kanji, yaitu 挨 [ai] dan 拶[satsu]. Karakter 挨 bermakna "mendorong dari belakang; mendorong ke depan; mendekatkan", dan 拶 bermakna hampir sama, yaitu "mendekati, dekat" dan "menempatkan A di antara B dan C". Menurut Ide $(1998,2007)$ istilah aisatsu bermakna asal "dialog", "pertukaran kata-kata", atau "tanya-jawab". Pemaknaan seperti ini dapat dimaknai bahwa aisatsu merupakan perangkat yang selalu digunakan dalam interaksi antarmanusia atau dalam komunikasi. Dengan demikian penggunaan aisatsu sangat berhubungan dengan peran sosial dan budaya. Oleh karena itu dalam artikel ini, saya tidak menggunakan istilah salam ataupun greetings mengingat adanya potensi perbedaan makna ataupun konsep dalam setiap budaya, sementara dalam budaya Jepang aisatsu mencakup lebih dari sekedar salam.

Dalam bahasa Jepang penggunaan aisatsu sudah diajarkan dan dibiasakan sejak kecil. Menurut Suzuki $(1978,1981)$ pada awalnya para orang tua dan guru mengajarkan bagaimana variasi dan penggunaan aisatsu dengan benar, kemudian pada perkembangannya baru mengajarkan penggunaan berdasarkan kesantunan. Penanaman penggunaan aisatsu yang sudah dilakukan sejak kecil menjadikan penggunaan aisatsu sangat alami. Orang Jepang seolah tidak menyadari bahwa mereka telah menggunakan aisatsu dalam setiap interaksinya dengan orang lain. Aisatsu sudah begitu tertanam dan membudaya dalam diri orang Jepang. Menurut Osamu (1995: 16) aisatsu adalah ungkapan yang digunakan untuk menjalin hubungan antarmanusia, atau untuk menjaga hubungan baik sesama manusia.

Dalam perwujudannya, orang Jepang melakukan aisatsu bukan sekedar dengan kata-kata, namun seringkali disertai dengan gerakan lain seperti membungkukkan badan atau gerakan tangan. Gerakan ini disebut Ojigi, yakni gerakan membungkukkan kepala dan badan dari sebatas pinggang. Secara bahasa ojigi berasal dari awalan $o$ yang berfungsi sebagai penanda sopan dan jigi yang bermakna harapan baik saat melakukan sesuatu (Amri, 2019). Gerakan menundukkan badan ini sebagai tanda patuh dan hormat kepada mitra tuturnya. Dengan ojigi dapat dikatakan bahwa orang Jepang sudah membuka diri dan siap untuk bekerja sama dalam rangka mewujudkan harmoni dengan mengedepankan sikap hormat serta menghindari segala bentuk konflik.

Penelitian ini membahas kompleksitas dari aisatsu, yakni variasi penggunaan aisatsu, baik dalam wujud, ragam, dan tujuannya. Kuraisin (2021) dalam penelitiannya tentang penggunaan aisatsu menyatakan bahwa aisatsu adalah ungkapan salam (greetings) yang berfungsi penting untuk menjaga dan memperkuat hubungan baik di antara orang-orang di dalam masyarakat. Penelitian Kuraisin lebih ditekankan pada pemakaian aisatsu sebagai salam (greetings) yang digunakan dalam berbagai situasi khususnya dalam pembelajaran bahasa Jepang. Kemudian Persson (2012) dalam penelitiannya tentang penggunaan aisatsu dalam peristiwa pernikahan orang Jepang. la menemukan bahwa tidak semua ekspresi yang digunakan dalam pidato pernikahan menggunakan aisatsu, sebagian besar fungsi aisatsu adalah fatis, dan aisatsu merupakan ungkapan yang bersifat tidak statis, ia berkembang baik dalam bentuk maupun fungsinya yang dapat dipengaruhi oleh budaya lain, khususnya budaya Barat. 
Penelitian ini tidak dikhususkan dalam bidang pembelajaran ataupun peristiwa khusus, seperti acara pernikahan, melainkan meneliti penggunaan aisatsu secara alamiah oleh orang Jepang dalam aktivitas mereka ketika mengikuti program summer couse di Indonesia. Secara khusus penelitian ini melihat bagaimana orang Jepang menggunakan aisatsu ketika berinteraksi dengan orang Jepang, orang Indonesia yang mengerti bahasa Jepang, dan orang Indonesia yang tidak mengerti bahasa Jepang. Hasil dari penelitian ini dapat memberikan gambaran penggunaan aisatsu ketika orang Jepang berada di luar lingkungan negara Jepang.

\section{Metode Penelitian}

Penelitian ini menerapkan metode etnografi untuk menemukan bagaimana penggunaan aisatsu dalam masyarakat Jepang. Data dikumpulkan dengan teknik observasi dan wawancara terhadap subjek penelitian. Subjek penelitian adalah dua orang penutur asli bahasa Jepang berjenis kelamin laki-laki yang sedang mengikuti program summer course di Semarang, Indonesia. Mereka adalah mahasiswa semester 5 Program Studi Hubungan Internasional dari universitas di Jepang. Mereka didampingi oleh seorang pembimbing dari Jepang tetapi tidak tinggal bersama selama di Semarang. Peneliti mendampingi mereka sebagai pemandu selama 3 hari sejak pagi keluar dari kamar kost hingga malam mereka kembali ke kamar kost. Dengan menggunakan alat perekam, foto, dan buku catatan, peneliti merekam aktivitas mereka selama berinteraksi, baik dengan sesama orang Jepang maupun dengan orang Indonesia. Kegiatan mereka selama 3 hari adalah mengikuti perkuliahan tentang budaya Indonesia, baik teori maupun praktik, memberi penyuluhan tentang budaya Jepang bagi mahasiswa dan siswa sekolah menengah atas, dan kegiatan wisata, serta kegiatan sehari-hari biasa seperti makan dan mengobrol santai.

Untuk menganalis penggunaan aisatsu digunakan teori etnografi komunikasi Hymes khususnya kerangka SPEAKING (Hymes, 1972; Saville-Traoke, 1997). Ancangan linguistik antropologi dipilih mengingat bahasa, termasuk di dalamnya aisatsu, adalah manifestasi dari budaya suatu bangsa ketika mereka berinteraksi atau berkomunikasi dengan sesama manusia. Potret bagaimana mereka menggunakan bahasa dalam kebudayaan mereka dapat terlihat jelas dengan ancangan linguistik antropologi. Melalui perspektif antropologis terhadap penggunaan aisatsu penelitian ini mencoba menjawab pertanyaan seperti: 1) apa itu aisatsu; 2) jenis aisatsu dan karakteristik, serta fungsinya; 3) siapa yang terlibat dalam penggunaan aisatsu; dan 4) situasi penggunaan aisatsu.

\section{Hasil dan Pembahasan}

Dari hasil observasi diketahui bahwa orang Jepang memang banyak sekali menggunakan aisatsu, baik dari segi kuantitas maupun variasi wujud dan ragamnya. Subjek menggunakan aisatsu untuk menyapa ketika mengawali percakapan, sebagai ritual khusus ketika berkenalan, permohonan izin, ungkapan maaf dan terima kasih, serta ungkapan empati. Variasi dalam aisatsu tidak hanya dari jenis penggunaannya, melainkan juga variasi dalam satu penggunaan yang sama. Sebagai contoh adalah ketika orang Jepang mengungkapkan permohonan maaf, mereka dapat mengungkapkan dengan Domo sumimasen, suimasen, shitsurei-shimasu, gomen, dan lain-lain. Ungkapan aisatsu juga bervariasi dalam ragamnya yang ditentukan oleh formalitas peristiwa. Formalitas tersebut ditentukan oleh resmi tidaknya acara, jauh dekat, dan tinggi rendah hubungan antarpartisipan.

Dari hasil wawancara tentang apa itu aisatsu dan mengapa orang Jepang nampak sering sekali menggunakan aisatsu, kedua subjek relatif menjelaskan dengan jawaban yang sama. Subjek 1 menjawab bahwa aisatsu itu mirip greetings dalam bahasa Inggris dan bagi orang Jepang sudah menjadi kebiasaan bagi orang Jepang dan dari kecil memang sudah diajari baik oleh orang tua maupun guru di sekolah untuk melakukan aisatsu dalam rangka selain untuk menghargai atau 
menghormati orang yang ditemui atau diajak bicara, juga agar mereka tidak dicap sebagai orang yang tidak mengenal etika. Kemudian subjek yang kedua menjawab bahwa aisatsu merupakan sapaan kepada orang lain sebagai bentuk kesopanan. Kalau tidak melakukan aisatsu akan dianggap sebagai orang yang tidak sopan. Artinya, dari kedua jawaban subjek dapat disimpulkan bahwa aisatsu merupakan ritual yang berkaitan dengan etika kesopanan masyarakat Jepang untuk menjaga harmoni dalam masyarakat dan agar tidak memperoleh label tidak sopan.

Peneliti dalam tulisan ini tidak menyebut aisatsu sebagai ungkapan verbal saja, melainkan juga ungkapan nonverbal, seperti gesture dan mimik muka yang menyertai ungkapan verbal aisatsu, bahkan ditemukan juga aisatsu yang hanya berupa gesture, sehingga peneliti dalam tulisan ini istilah ungkapan aisatsu tidak hanya merujuk pada istilah kebahasaan saja.

Tabel 1 Penggunaan Aisatsu

\begin{tabular}{|c|c|c|c|}
\hline No. & Penggunaan & Variasi ungkapan dan tindakan & Tindak \\
\hline 1. & $\begin{array}{l}\text { Sapaan untuk mengawali } \\
\text { interaksi }\end{array}$ & $\begin{array}{l}\text { Ohayo; Ohayo gozaimasu; } \\
\text { Konnichiwa; Konbanwa } \\
\text { ii otenki desu ne; Atsui desu ne; } \\
\text { Samui desu ne; odekake desu ka }\end{array}$ & $\begin{array}{l}\text { Formal: ojigi } \\
\text { Nonformal: menganggukkan } \\
\text { kepala, gerakan tangan, mimik } \\
\text { muka (ramah/tersenyum) }\end{array}$ \\
\hline 2. & Ritual berkenalan & $\begin{array}{l}\text { Hajimemashite, Yoroshiku } \\
\text { onegaishimasu; }\end{array}$ & Ojigi \\
\hline \multirow[t]{5}{*}{3.} & Permohonan izin & & \\
\hline & - Memasuki ruangan & Shitsurei-shimasu & Formal: ojigi \\
\hline & - Menyela pembicaraan & Sumimasen ga; Shitsurei-shimasu & $\begin{array}{l}\text { Nonformal: gerakan tangan, } \\
\text { mimik muka }\end{array}$ \\
\hline & - Melewati jalan & Shitsurei-shimasu & \\
\hline & $\begin{array}{ll}\text { - } & \text { Meninggalkan } \\
\text { pertemuan } \\
\text { - } \quad \text { Memulai percakapan }\end{array}$ & $\begin{array}{l}\text { (Ja/Dewa) Shitsurei-shimasu; } \\
\text { Sayonara; (Ja/Dewa) mata; Ja kore de }\end{array}$ & \\
\hline \multirow[t]{3}{*}{4.} & $\begin{array}{l}\text { Ungkapan perasaan maaf dan } \\
\text { terima kasih }\end{array}$ & & \\
\hline & - Meminta maaf & $\begin{array}{l}\text { (Domo) Sumimasen; Shitsurei- } \\
\text { shimasu; Gomen }\end{array}$ & ojigi \\
\hline & $\begin{array}{l}\text { - Mengucapkan terima } \\
\text { kasih }\end{array}$ & $\begin{array}{l}\text { Domo arigato-gozaimasu; Arigato- } \\
\text { gozaimasu; Arigato-gozaimashita; } \\
\text { Arigato }\end{array}$ & \\
\hline 5. & Ungkapan empati & $\begin{array}{l}\text { Omedeto-gozaimasu; Oyorokobi- } \\
\text { moshiagemasu; Okuyami- } \\
\text { moshiagemasu; Taihen desu ne }\end{array}$ & ojigi \\
\hline
\end{tabular}

\subsection{Aisatsu sebagai sapaan}

Aisatsu sebagai sapaan adalah aisatsu yang biasa dikenal sebagai greetings dalam bahasa Inggris ataupun salam dalam bahasa Indonesia. Aisatsu ini digunakan sebagai ungkapan salam ketika bertemu dengan seseorang atau ketika mengawali sebuah pertemuan. Greetings menurut Duranti (1997a, 1997b) selalu ada dalam setiap budaya tanpa memandang jenis kelamin, usia, bangsa, atau wilayah. Namun tentu saja terdapat beberapa hal spesifik yang berbeda terkait realisasi pilihan leksikal dan cara menuturkannya. Dalam budaya yang sama penggunaan aisatsu sebagai salam untuk mengawali interaksi mungkin tidak bermasalah karena sudah menjadi bagian dari kompetensi budaya. Hal ini dapat berlaku berbeda jika interaksi dilakukan dengan orang dari budaya yang berbeda, meskipun dalam hal esensinya sama, yakni sebagai pembuka percakapan atau interaksi. Seperti apa yang dinyatakan oleh Pillet-Shore (2008), salam adalah sarana bagi calon peserta percakapan untuk beralih dari situasi individual ke situasi sosial. Dengan kata lain, pertukaran 
sapaan secara verbal memungkinkan peserta percakapan untuk memberi sinyal bahwa mereka telah melewati batas antara tidak berinteraksi dan akan berinteraksi.

Dari hasil observasi selama pengumpulan data ditemukan beberapa jenis aisatsu yang berfungsi sebagai sapaan. Sapaan yang ditemukan berupa salam yang menunjukkan waktu, menanyakan kabar, sapaan tertentu yang berkaitan dengan cuaca atau kegiatan mitra tutur.

Dalam bahasa Jepang aisatsu yang umum sebagai salam adalah Ohayo-gozaimasu 'Selamat pagi', Konnichiwa 'Selamat siang', dan Konbanwa 'Selamat malam'. Aisatsu ini hanya digunakan ketika mengawali pertemuan dan tidak digunakan ketika berpisah. Hal ini sama dengan penggunaan greetings dalam bahasa Inggris yang hanya digunakan di awal pertemuan, bukan sebagai ungkapan perpisahan atau pamitan (Duranti, 1997), sementara dalam bahasa Indonesia ungkapan salam dapat digunakan untuk mengawali maupun mengakhiri pertemuan.

- Ohayo-gozaimasu

Aisatsu Ohayo-gozaimasu diucapkan oleh subjek 1 dan 2, bergantian ketika diadakan pertemuan dengan sejumlah mahasiswa Sastra Jepang di kelas. Di depan kelas mereka mengucapkan aisatsu dengan melakukan ojigi sebentar, kemudian tersenyum dan tertawa sambil melambaikan tangan karena sambutan antusias dari mahasiswa. Dari segi usia subjek dan mahasiswa tidak banyak berbeda. Dari segi hubungan antara subjek dan mahasiswa tidak ada kedekatan karena kedua pihak baru saja bertemu, akan tetapi setelah subjek melakukan aisatsu dan memperkenalkan diri, kedua pihak berangsur akrab. Keakraban ini muncul karena faktor kesamaan usia, minat, dan bahasa Jepang. Subjek merasa senang karena para mahasiswa yang sedang belajar bahasa Jepang sangat antusias dalam menyambut mereka dengan menggunakan bahasa Jepang. Dari pihak mahasiswa mereka juga senang dan antusias karena bertemu dengan orang Jepang yang sebaya dan dapat memraktikkan bahasa Jepang mereka.

Penggunaan ragam hormat dan sopan, serta dilakukan dengan ojigi menandakan situasi formal. Formalitas peristiwa dilandaskan pada lokasi pertemuan yang berada di kelas di sebuah perguruan tinggi, formalitas acara yang diselenggarakan oleh perguruan tinggi, dan faktor partisipan pembicaraan yang saat itu dihadiri oleh pejabat perguruan tinggi, dosen, pembimbing mereka, dan mahasiswa, serta faktor hubungan antarpartisipan yang baru pertama kali bertemu.

Aisatsu Ohayo-gozaimasu juga digunakan oleh subjek ketika mereka bertemu dengan pembimbing mereka, pejabat perguruan tinggi, dan para dosen. Ketika mereka bertemu antarsubjek, yang digunakan adalah ohayo. Ini diungkapkan oleh mereka ketika pagi hari mereka bertemu di ruang tamu tempat kost mereka. Mereka juga menggunakan ohayo saja ketika bertemu dengan para mahasiswa di hari kedua dan ketiga di kampus. Penggunaan ragam biasa ini menandakan adanya suasana keakraban dan situasi nonformal. Penggunaannya pun tanpa disertai ojigi. Bahkan tampak juga mereka melakukan aisatsu dengan berjabat tangan, melambaikan tangan, dan mempertemukan kedua tangan mereka (tos).

- Konnichiwa dan Konbanwa

Wujud aisatsu yang lain yang digunakan ketika bertemu adalah Konnichiwa dan Konbanwa. Konnichiwa diucapkan ketika bertemu dengan orang lain pada waktu siang hari, dan konbanwa pada malam hari. Keduanya diekspresikan dalam wujud yang sama baik dalam situasi formal maupun nonformal. 
Apabila kita perhatikan ketiga aisatsu yang digunakan sebagai ungkapan salam yang berhubungan dengan waktu pertemuan, makna harfiah ketiganya tidak berkaitan dengan ucapan salam atau selamat. Ohayo-gozaimasu merupakan bentuk ragam hormat dari ajektiva hayai yang berarti 'cepat/segera/awal'. Ini merupakan ucapan yang mengandung pujian kepada mitra tutur yang sudah bangun pagi dan beraktivitas di pagi hari. Kemudian dua salam berikutnya yaitu Konnichiwa 'Selamat siang' dan Konbanwa 'Selamat malam" juga tidak berkaitan dengan salam. Konnichiwa berasal dari yaitu konnichi 'hari ini' dan kata bantu wa yang berfungsi sebagai penanda topik kalimat. Demikian juga dengan Konbanwa, konban berarti 'malam ini' dan wa adalah penanda topik. Apabila dilihat dari segi sintaksis maka sebenarnya baik Konnichiwa maupun Konbanwa bukanlah ungkapan yang lengkap. Ungkapan lengkapnya adalah menanyakan kabar atau kesehatan pada waktu itu yang dalam bahasa Jepangnya adalah "Konnichi/Konban wa gokigen ikaga desu ka" yang bermakna 'Hari (siang)/Malam ini, bagaimana keadaan Anda?'.

Wujud lain aisatsu yang ditemukan sebagai sapaan adalah:

- "Ogenki desuka” (Apa kabar?)

- " "li otenki desu ne" (Cuacanya bagus ya)

- "Atsui desu ne" (Panas ya)

- "Samui desu" (Dingin ya)

- "Odekake desu ka" (Mau pergi?

Dari hasil analisis terhadap tindakan aisatsu ketika seseorang bertemu dengan orang lain, peneliti menyimpulkan bahwa aisatsu ini merupakan sebuah pesan sebagai tanda kepada calon mitra tuturnya bahwa ia akan beralih memasuki wilayah interaksi sosial dari yang sebelumnya individual. Penutur menunggu tanggapan dari calon mitra tuturnya sebagai tanda penerimaan atau persetujuan masuknya wilayah interaksi sosial bersama. Orang yang menginisiasi aisatsu adalah orang yang mendatangi lokasi percakapan atau memasuki percakapan. Sebagai pendatang penutur memposisikan dirinya sebagai pihak yang akan memasuki wilayah otoritas calon mitra tutur karena lebih dahulu berada di lokasi pembicaraan. Ini sejalan dengan apa yang disampaikan oleh Firth (1972:30), bahwa greetings adalah 'sistem tanda yang menyampaikan lebih dari sekedar pesan terbuka.'

\subsection{Aisatsu sebagai ritual berkenalan}

Aisatsu yang digunakan ketika berkenalan adalah Hajimemashite yang kemudian diakhiri dengan Yoroshiku onegaishimasu. Aisatsu ini diungkapkan secara sopan dengan melakukan ojigi sebagai bentuk penghormatan kepada mitra tuturnya yang baru ditemui. Dalam bahasa Indonesia ungkapan ini sering diartikan dengan "Perkenalkan" ataupun "Salam kenal" meskipun sebenarnya secara harfiah ungkapan ini berasal dari bentuk te (bentuk sambung) dari hajimeru yang berarti 'memulai'. Barangkali maksudnya adalah sebagai ungkapan bahwa ini adalah awal pertemuan yang masih akan terus berlanjut.

Aisatsu Hajimemashite biasanya diakhiri dengan Yoroshiku onegaishimasu setelah penutur menyebutkan identitasnya. Secara harfiah ungkapan ini terdiri dari dua kata, yakni yoroshiku yang merupakan adverbia yang berarti 'dengan baik' serta onegaishimasu yang berarti meminta tolong. Dengan demikian ungkapan tersebut dapat diartikan "Tolonglah (saya) dengan sebaik-baiknya". Dalam budaya Indonesia mungkin ketika orang baru berkenalan dan kemudian meminta agar ditolong dengan baik akan dianggap tidak sopan meskipun diucapkan dengan ragam hormat. Namun, maksud dari ungkapan ini sebenarnya adalah ungkapan keinginan dari penuturnya bahwa 
ia sangat menginginkan hubungan yang baik dengan mitra tuturnya dimulai dari saat perkenalan tersebut, sehingga ungkapan ini biasanya dimaknai dengan "Senang berkenalan dengan Anda". Ungkapan Yoroshiku onegaishimasu juga digunakan sebagai ungkapan penutup ketika seseorang meminta pertolongan.

\subsection{Aisatsu dilakukan ketika penutur mempunyai kepentingan atau maksud tertentu terhadap mitra tutur}

Ketika orang Jepang mempunyai kepentingan atau maksud tertentu pada umumnya mereka akan mengawalinya dengan aisatsu. Pada dasarnya aisatsu kategori ini adalah tanda atau sinyal dari penutur bahwa ia akan memasuki wilayah otoritas orang lain. Kepentingan atau maksud tertentu di sini di antaranya adalah sebagai berikut.

\subsubsection{Ketika akan memasuki ruang sementara ruang tersebut ada pemiliknya atau sedang digunakan oleh orang lain}

Aisatsu jenis ini ditemukan ketika subjek dan pembimbingnya akan ke ruang dosen bahasa Jepang dan ke ruang pimpinan fakultas. Wujud aisatsu yang digunakan adalah Shitsurei-shimasu dan aisatsu yang sama ketika mendatangi pertemuan, seperti ohayo-gozaimasu dan konnichiwa. Mereka melakukannya dengan cara ojigi. Ketika mereka memasuki ruang dosen lain, ruang guru, dan ruang kepala sekolah mereka tidak menggunakan bahasa Jepang tetapi tetap dengan ojigi yang kemudian dilanjutkan dengan berjabat tangan. Meskipun mereka menggunakan bahasa Indonesia tetapi ternyata tidak meninggalkan tindak ojiginya ketika mengungkapkan aisatsu.

Shitsurei bermakna harfiah 'kasar' atau 'tidak sopan' (kata sifat) dan bentuk verbanya adalah dengan menambahkan verba bantu suru atau shimasu (bentuk sopan), yang bermakna 'melakukan'. Dalam penggunaannya ungkapan ini digunakan ketika akan melakukan perbuatan yang berpotensi mengganggu orang lain seperti memasuki ruangan ketika di dalamnya ada orang, ketika akan melewati orang lain, ataupun ketika akan duduk di sekitar orang lain yang sudah lebih dahulu duduk. Dengan demikian ungkapan aisatsu ini sebenarnya ungkapan permohonan maaf penutur karena tindakan yang akan dilakukannya mengganggu mitra tutur, namun ia tetap harus melakukannya karena ada kepentingan/kebutuhan. Dalam bahasa Indonesia ungkapan ini dapat dipadankan dengan 'permisi.

\subsubsection{Ketika akan menyela pembicaraan ketika pembicaraan sedang berlangsung}

Aisatsu yang digunakan dalam jenis ini adalah Sumimasen ga dan Shitsurei-shimasu. Sumimasen adalah salah satu ungkapan yang digunakan sebagai permohonan maaf, seperti juga Shitsureishimasu. Ungkapan Sumimasen dituturkan ketika penutur telah melakukan perbuatan salah atau akan melakukan perbuatan yang menurut perkiraan penutur akan mengganggu mitra tuturnya. Dalam hal penggunaan yang kedua, biasanya dituturkan di awal dan disertai dengan partikel ga. Partikel ga di sini berfungsi sebagai konjungsi yang bermakna "tetapi". Ketika penutur mengungkapkan aisatsu Sumimasen ga (maaf/permisi, tapi...), berarti ia memotong pembicaraan atau meminta waktu untuk berbicara pada saat pembicaraan berlangsung. Setelah mengungkapkan aisatsu tersebut biasanya dilanjutkan dengan permohonan ataupun permintaan tolong.

\subsubsection{Ketika akan melewati jalan yang di sekitarnya ada orang}

Aisatsu Shitsurei-shimasu juga ditemukan ketika subjek akan melewati jalan dan tangga kampus yang di sekitarnya terdapat mahasiswa. Aisatsu ini diungkapkan dengan sedikit menundukkan badan bersamaan dengan pengucapan Shiturei-shimasu. Sama seperti dalam 3.3.1 aisatsu ini 
digunakan sebagai permohonan sopan untuk melewati jalan. Di dalam data juga ditemukan bahwa ketika subjek melewati jalan di mana di situ terdapat orang yang tidak dikenalnya, subjek tetap melakukan aisatsu dengan menundukkan badan dan tersenyum tanpa mengucapkan kata-kata. Subjek tidak mengucapkan aisatsu karena orang yang berada di lokasi tersebut adalah orang Indonesia.

\subsubsection{Meninggalkan pertemuan}

Aisatsu yang digunakan ketika berpisah, yakni yang diucapkan oleh orang yang berinisiatif meninggalkan pertemuan atau berpamitan disebut wakare no aisatsu. Wakare no aisatsu juga merupakan tanda permohonan izin bagi mitra tuturnya untuk meninggalkan wilayah sosial bersamanya. Ja, mata ataupun Dewa, mata diucapkan oleh subjek ketika mereka berpisah dengan mitra tuturnya. Variasi yang lain adalah $J a$, mata ne... atau hanya mata ne..., yakni dengan menambahkan partikel ne di belakang yang bermaksud menginginkan persetujuan dari mitra tuturnya. Ja atau Dewa sebenarnya ungkapan untuk menyimpulkan, dalam bahasa Indonesia dapat disepadankan dengan "kalau begitu" dan mata bermakna 'lagi'. Penggunaan dewa lebih formal dibandingkan dengan ja. Dari data yang ditemukan subjek menggunakan dewa hanya ketika mau berpisah dengan peneliti, pada penggunaan dengan mitra tutur mahasiswa dan juga siswa-siswi sekolah menengah mereka menggunakan Ja, mata. Dalam situasi yang lebih formal mereka menggunakan aisatsu shitsurei-shimasu ketika akan meninggalkan pertemuan.

Wujud lain wakare no aisatsu yang ditemukan adalah Ja, kore de dan Sayonara. Ja, kore de diucapkan sekali oleh subjek 1 pada saat mengakhiri pertemuan kelas ketika mempresentasikan budaya Jepang di hadapan siswa-siswi sekolah menengah. Kemudian aisatsu Sayonara diucapkan oleh subjek 1 dan 2 kepada siswa-siswi sekolah menengah ketika mereka akan meninggalkan sekolah dan diucapkan kepada para mahasiswa dan peneliti ketika mereka akan meninggalkan kota Semarang. Sayonara yang berarti 'Selamat Tinggal' memang digunakan untuk perpisahan dalam jangka waktu lama atau perpisahan yang penuturnya tidak mengetahui apakah mereka akan dapat bertemu lagi atau tidak.

Variasi ragam aisatsu ditentukan oleh faktor siapa yang berbicara dan siapa yang diajak bicara, serta formalitas pembicaraan. Penutur menggunakan ragam sopan atau hormat ketika yang diajak bicara adalah orang yang lebih tua atau berkuasa. Penutur juga menggunakan ragam sopan atau hormat ketika dalam situasi formal.

\subsection{Aisatsu sebagai ungkapan perasaan maaf dan terima kasih}

\subsubsection{Permohonan maaf;}

Aisatsu permohonan maaf diungkapkan ketika subjek merasa telah berbuat salah, mengganggu mitra tutur, ataupun telah membuat sesuatu yang dipandang oleh subjek memberatkan mitra tuturnya (Saifudin, 2009). Aisatsu ini juga diungkapkan ketika subjek akan melakukan sesuatu atau membutuhkan sesuatu yang dipandangnya akan mengganggu atau memberatkan mitra tuturnya. Variasi yang ditemukan adalah (Domo) Sumimasen, Shitsurei-shimasu, dan Gomen. Dua yang pertama diungkapkan dalam peristiwa formal, yakni ketika dalam acara formal, mitra tutur yang lebih tinggi kedudukannya dari pada penutur, serta topik pembicaraan yang formal. Sementara aisatsu yang terakhir digunakan dalam situasi akrab atau tidak formal. 


\subsubsection{Ungkapan terima kasih}

Ungkapan terima kasih merupakan bentuk apresiasi, rasa syukur, ataupun pengakuan atas kebaikan yang diterima dari pihak lain (Saifudin, 2005, 2010). Ungkapan terima kasih yang ditemukan di dalam data adalah dengan menuturkan (Domo) Arigato-gozaimasu dan Sumimasen. Arigato-gozaimasu merupakan bentuk hormat dan formal dari ajektiva arigatai yang berarti 'menguntungkan, hal yang disyukuri'. Dalam penggunaannya secara umum disertai dengan membungkukkan badan (ojigi). Variasi penggunaan aisatsu ini dari yang paling hormat, yakni Domo arigato-gozaimasu, Arigato-gozaimasu, Arigato-gozaimashita, dan Arigato. Tiga yang pertama adalah ragam hormat dan formal (sopan), dan yang terakhir adalah ragam akrab. Subjek juga terkadang menggunakan ungkapan sankyu yang merupakan serapan dari bahasa Inggris Thank you, ketika berbicara dengan mahasiswa yang sudah akrab. Peneliti juga menemukan ungkapan dalam bentuk lampau, yakni Arigato-gozaimashita yang dituturkan oleh subjek kepada peneliti dan para mahasiswa pada saat acara perpisahan. Aisatsu dituturkan secara khidmat dengan menundukkan badan lebih rendah dari biasanya.

Satu hal yang menarik adalah ungkapan Sumimasen yang biasanya digunakan sebagai permohonan maaf, ternyata juga digunakan sebagai aisatsu terima kasih. Hal ini ditemukan ketika salah seorang mahasiswa mengambilkan tas salah satu subjek yang tertinggal di salah satu ruang kelas kampus pada saat subjek sudah berada di dalam bus yang akan berangkat ke sekolah menengah. Meskipun tidak dalam situasi formal dan mitra tuturnya adalah mahasiswa sebaya, subjek tetap menggunakan ragam hormat dan formal. Dari sini dapat disimpulkan bahwa aisatsu Sumimasen digunakan ketika penutur merasa berterima kasih atas kebaikan mitra tutur sekaligus juga ungkapan permohonan maaf karena dalam kebaikan yang diterimanya telah memberatkan mitra tuturnya.

\subsection{Aisatsu dilakukan pada keadaan, peristiwa, atau kondisi khusus tertentu}

Orang Jepang dikenal sangat murah dan sering sekali menanggapi keadaan yang dialami, terjadi, atau menimpa seseorang. Keadaan tersebut bukan hanya yang menyenangkan tetapi juga yang menyedihkan. Inilah yang disebut ungkapan empati (Saifudin, 2019), yakni turut merasakan hal sama dengan pihak yang diberikan ungkapan empati. Pada saat peristiwa-peristiwa penting seperti tahun baru, ulang tahun, pernikahan, dan hari kedewasaan, orang Jepang akan melakukan aisatsu sebagai ungkapan empati kebahagiaan bersama dalam peristiwa tersebut. Sebaliknya pada saatsaat seperti adanya kematian, sakit, tertimpa bencana, dan kondisi-kondisi lain yang dianggap memberatkan mitra tutur, orang Jepang juga akan memberikan ungkapan aisatsu sebagai tanda turut merasakan apa yang dirasakan oleh mitra tutur. Aisatsu biasanya disertai dengan sikap ojigi yang kadar membungkuknya sesuai dengan empati yang dibagikan. Wujud aisatsu yang ditemukan adalah sebagai berikut.

\subsubsection{Omedeto-gozaimasu}

Aisatsu ini digunakan sebagai ungkapan selamat kepada seseorang yang sedang menikmati momentum kebahagiaan, seperti saat ulang tahun, menikah, wisuda, ataupun ketika sukses melakukan pekerjaan tertentu. Dalam situasi akrab hanya diungkapkan dengan Omedeto.

\subsubsection{Oyorokobi-moshiagemasu}

Oyorokobi moshiagemasu merupakan ungkapan perasaan penutur yang turut merasakan kesenangan atau kebahagiaan yang dirasakan oleh mitra tutur. Yorokobi berarti 'senang atau 
bahagia' dan o moshiagemasu adalah bentuk hormat (humble) dari suru yang berarti 'melakukan'. Ungkapan ini dapat digunakan sendiri atau melengkapi ucapan selamat seperti dalam 3.3.2.

\subsubsection{Okuyami-moshiagemasu}

Aisatsu ini merupakan kebalikan dari 3.3.3, yakni untuk mengungkapkan perasaan turut bersedih, berduka, atau simpati atas situasi atau peristiwa sedih atau duka yang dialami oleh mitra tutur. Kuyami bermakna 'bela sungkawa' dan dalam bahasa Indonesia ungkapan ini dapat disepadankan dengan "Turut berduka cita" atau "Ikut berbela sungkawa".

\subsubsection{Taihen desu ne}

Aisatsu ini digunakan ketika melihat mitra tutur sedang mengalami kesulitan atau melakukan sesuatu yang berat. Taihen sendiri bermakna 'sangat' yang digunakan sebagai keterangan untuk aktivitas ataupun kondisi yang ekstrim, misalnya mengangkat barang yang berat dan melakukan pekerjaan yang sangat menyibukkan.

\section{Simpulan}

Tulisan ini telah memberikan gambaran tentang bagaimana aisatsu digunakan. Dari hasil observasi peneliti terhadap dua orang subjek penelitian, penggunaan aisatsu di dalam masyarakat Jepang dan di luar Jepang dengan masyarakat bukan orang Jepang tidak banyak berbeda. Perbedaan hanya tampak pada ragamnya yang lebih sopan. Hal ini dimaklumi mengingat situasinya bagi subjek orang-orang yang berinteraksi dengan mereka kebanyakan adalah orang Indonesia. Mereka menjaga jarak dengan menggunakan ragam sopan agar situasinya lebih formal.

Penggunaan aisatsu berdasarkan temuan penelitian ini adalah digunakan sebagai ungkapan sapaan untuk mengawali percakapan, ritual dalam perkenalan, permohonan izin, ungkapan maaf dan terima kasih, serta ungkapan empati pada keaadaan, peristiwa, maupun kondisi tertentu yang dialami mitra tutur. Dalam kaitannya dengan penggunaan sebagai sapaan, aisatsu merupakan sebuah tanda atau sinyal dengan tujuan untuk mengungkapkan keinginan penutur kepada mitra tutur menjalin komunikasi, demikian juga halnya dengan penggunaan berikutnya sebagai ritual dalam perkenalan. Dalam berkenalan, ungkapan Hajimemashite yang diakhiri dengan Yoroshiku onegaishimasu adalah tanda bahwa penutur mempunyai keinginan dan membuka diri menjalin komunikasi kepada mitra tuturnya yang dimulai pada saat berkenalan.

Aisatsu juga bermakna tanda meminta izin memasuki wilayah otoritas dari mitra tutur. Aisatsu jenis ini dilakukan ketika penutur mempunyai kepentingan tertentu, sementara pada saat itu sudah ada mitra tutur yang dipandangnya mempunyai otoritas, seperti sudah ada pihak lain yang lebih dahulu berada di lokasi ataupun sudah ada percakapan yang berlangsung. Selain itu, Aisatsu juga digunakan sebagai ungkapan perasaan penutur ketika merasa bersalah atau berterima kasih, serta ungkapan empati, yaitu sebuah ungkapan yang merefleksikan perasaan sama dengan mitra tuturnya atau turut merasakan apa yang dirasakan oleh mitra tuturnya. Bagi orang Jepang aisatsu adalah norma kemasyarakatan atau budaya yang harus ditaati untuk menjaga harmoni dalam masyarakat. Orang yang tidak mengikuti norma seperti ini akan dicap sebagai orang yang tidak mematuhi aturan.

Dari pemaparan hasil analisis data, nampak bahwa sebenarnya aisatsu adalah sebuah ritual yang merupakan cerminan budaya masyarakat Jepang yang berkaitan erat dengan norma kesopanan atau etika. Aisatsu diungkapkan tidak hanya secara verbal namun juga nonverbal, berupa gesture, mimik muka, dan lain-lain. Kemudian, dengan melihat bahwa beberapa ungkapan verbal dalam 
bahasa Jepang yang artinya berbeda dengan makna harfiahnya, juga ditemukan aisatsu tanpa ungkapan verbal, dapat disimpulkan bahwa sebenarnya aisatsu hanyalah sebuah tanda dalam kaitannya dengan etika kesopanan yang mengungkapkan keterbukaan penutur bahwa ia siap berinteraksi dan berharap yang sama dengan mitra tuturnya.

\section{Referensi}

Amri, M. (2019). Ojigi : The Ethics of Japanese Community's Nonverbal Language. Advances in Social Science, Education and Humanities Research, 380(3rd Social Sciences, Humanities, and Education Conference (SoSHEC 2019)), 38-41.

Duranti, A. (1997a). Linguistic Antropology. Cambridge University Press.

Duranti, A. (1997b). Universal and Culture-Specific Properties of Greetings. Journal of Linguistic Anthropology, 63-97.

Hymes, D. (1972). The ethnography of speaking. In J. A. Fishman (Ed.), Reading in the Sociology of Language. The Hague Mouton.

Ide, R. (1998). "Sorry for your kindness": Japanese interactional ritual in public discourse. Journal of Pragmatics, 29, 509-529.

Ide, R. (2007). Aisatsu. In Handbook of Pragmatics Online.

Kuraesin, U. (2021). "Aisatsu" in Japanese Language Education. Turkish Journal of Computer and Mathematics Education, 12(11), 1250-1255.

Osamu, M. (1995). Nihonjijou Handobukku. Daishuukanshoten.

Persson, Z. (2012). The Complexity of Aisatsu. Lund University.

Pillet-Shore, D. (2008). Coming Together: Creating and Maintaining Social Relationships through the Openings of Face-To-Face interactions. Disertasi tidak dipublikasikan. University of California, Los Angeles.

Saifudin, A. (2005). Faktor Sosial Budaya dan Kesopanan Orang Jepang dalam Pengungkapan Tindak Tutur Terima Kasih pada Skenario Drama Televisi Beautiful Life Karya Kitagawa Eriko [Universitas Indonesia]. https://doi.org/10.13140/RG.2.2.13134.56643

Saifudin, A. (2009). Variasi Kesantunan Penggunaan Ungkapan Permohonan Maaf dalam Bahasa Jepang. LITE: Jurnal Bahasa, Sastra, Dan Budaya, 5(1), 45-57. http://publikasi.dinus.ac.id/index.php/lite/article/view/1343

Saifudin, A. (2010). Analisis Pragmatik Variasi Kesantunan Tindak Tutur Terima Kasih Bahasa Jepang dalam Film Beautiful Life Karya Kitagawa Eriko. Lite: Jurnal Bahasa, Sastra, Dan Budaya, 6(2), 172-181.

Saifudin, A. (2019). Deiksis Bahasa Jepang dalam Studi Linguistik Pragmatik. Japanese Research on 
Linguistics, Literature, and Culture, 2(1), 16-35. https://doi.org/10.33633/jr.v2i1.3348

Saville-Traoke, M. (1997). The Ethnographic Analysis of Communicative Events. In N. Coupland \& A. Jaworski (Eds.), Sociolinguistics: A Reader and Course Book (pp. 126-144). Macmillan Press.

Suzuki, T. (1978). Words in Context: A Japanese Perspective on Language and Culture. Kodansha International.

Suzuki, T. (1981). Aisatsu to kotoba. In Kotoba shiriizu 14. Henshuu Bunkachou. 